location for the mutation in the first family was in the NF1 gene, whereas that in the second family was excluded from the NF1 locus, although the phenotype was similar to that of family 1. (Pulst SM, Riccardi VM et al. Familial spinal neurofibromatosis: clinical and DNA linkage analysis. Neurology Dec 1991; 41:1923-1927.) (Reprints: Dr. Pulst, Div Neurol, Cedars-Sinai Medical Center, 8700 Beverly Blvd., Los Angeles, CA 90048.)

COMMENT. Studies of families in which all affected individuals express the same subset of the NF phenotype allow a correlation between the mutation and its clinical characteristics. Symptomatic spinal neurofibromas occur in less than $5 \%$ of patients with NF1, but are commonly found in NF2. This may be the first report of familial spinal neurofibromatosis in families with NF1. One individual in each pedigree developed a neurofibrosarcoma and died of its complications. This is a rare complication in NF1, explained by the authors as a familial predisposition related to the mutations.

\title{
CUTANEOUS GRANULOMAS AND ATAXIA-TELANGIECTASIA
}

Development of cutaneous granulomas in 8 patients with ataxiatelangiectasia is reported from the Departments of Pediatrics and Dermatology, Northwestern University Medical School, Chicago, IL; the Hospital for Sick Children, Toronto, Canada; Henry Ford Hospital, Detroit, MI; and University of North Carolina, Chapel Hill. The granulomas were atrophic lesions that frequently became encrusted and ulcerative. Their appearance differed significantly from the well circumscribed annular plaques or skin colored subcutaneous nodules of typical granuloma annulare. The lesions were persistent rather than self-limited and no infectious organisms were demonstrated. Treatment with intravenous immune globulin, topical antibiotic therapy and topical corticosteroid therapy were unsuccessful. The authors postulate that the granulomas were an attempt to localize antigen in patients with a dysfunctional immune system. (Paller AS et al. Cutaneous granulomatous lesions in patients with ataxia-telangiectasia. J Pediatr Dec 1991; 119:917-922.) (Reprints: Dr. Paller, Division of Dermatology, Children's Memorial Hospital, 2300 Children's Plaza, Chicago, IL 60614.)

COMMENT. Patients with ataxia-telangiectasia have dysfunction of humoral and cell-mediated immunity as demonstrated by an immature thymus; absent or small tonsils; low levels of immunoglobulins A, E, $\mathrm{G} 2$ and $\mathrm{G} 4$; and a poor response to antigenic stimulation.

\section{SEIZURE DISORDERS}

\section{AUTISM AND EPILEPSY}

The prevalence and clinical manifestations of epilepsy in 302 autistic and 237 dysphasic, non-autistic children were studied at the Departments of Neurology and Pediatrics, Albert Einstein College of Medicine and Montefiore 